\section{Evaluation of antibacterial activity of essential oil from Algerian Pistacia lentiscus resin}

\section{G. Bachir Raho*}

Department of Biology, University of Mascara, BP 305 Route de Mamounia Mascara, Mascara 29000, Algeria

\begin{abstract}
The purpose of this research was to evaluate the in vitro antibacterial activity of the essential oils from the resin of Pistacia lentiscus against Staphylococcus aureus (Grampositive bacteria) and Escherichia coli (Gram-negative bacteria). The agar disc diffusion method was used for microbial growth inhibition at various dilutions of the oils.

Results showed that the tested essential oils possess antibacterial activity against $S$. aureus but inactive on $E$. coli. These results may have significant implications for the future development of resin oils of $P$. lentiscus as an antimicrobial agent for the treatment of the infections caused by $S$. aureus.
\end{abstract}

Key words:

Resin, Pistacia lentiscus, essential oil, antibacterial activity, Staphylococcus aureus, Escherichia coli

\author{
Received: \\ 02 May 2017 \\ Accepted: \\ 30 May 2017 \\ Published: \\ 02 June 2017 \\ *Corresponding Author: \\ G. Bachir Raho \\ Department of Biology, \\ University of Mascara, BP \\ 305 Route de Mamounia \\ Mascara, Mascara 29000, \\ Algeria \\ Email: \\ bachir_raho \\ @yahoo.fr \\ Citation: \\ Bachir Raho, G. (2017). \\ Evaluation of antibacterial \\ activity of essential oil \\ from Algerian Pistacia \\ lentiscus resin. \\ Journal of Medicinal \\ Botany, 1, 13-19. doi: \\ 10.25081/jmb.2017.v1.43
}

\section{Introduction}

The major threat in the treatment of infectious diseases is that the pathogens sometimes become drug resistant (Owlia et al., 2009). Staphylococcus aureus and Escherichia coli are two pathogens that are associated with serious community-acquired disease (Enright et al., 2000; Oteo et al., 2008). The Gram-positive Bacterium $S$. aureus is the most dangerous of staphylococcal bacterial infections that causes a variety of diseases in animals and humans (Parvizi et al., 2012). This is common in infections, pneumonia and other threatening conditions and even food poisoning (Embrey et al., 2004). Several studies have documented increasing resistance rates in $S$. aureus and E. coli to antibiotics (Waters et al., 2011; de Kraker et al., 2011; Gagliotti et al., 2011; Tadesse et al., 2011; Chambers and Deleo, 2009; Karou et al., 2010; Hossain et al., 2008). Synthetic drugs are mainly used but there are increased chances of side effects and other poisoning conditions on human health (Rodrigues et al., 2013). In this context, it become necessary to findout alternative methods to develop antibacterial agents especially from plants and plant based products (Bachir et al., 2017).

The genus Pistacia comprises about 70 genera and over 600 species and belongs to the Anacardiaceae family (Hormaza and Wünsch, 2011). Among 15 species of pistachios, only 4 species grow in Algeria, including Pistacia lentiscus, Pistacia terebinthus, Pistacia atlantica and Pistacia vera (Belhadj, 1999). Pistacia lentiscus L. commonly known as mastic tree or lentisk is a dioecious evergreen shrub that grows up to 3 to $4 \mathrm{~m}$ in height and widely distributed throughout the Mediterranean area (Mezni et al., 2012; Koç et al., 2014a). P. lentiscus grows north of Algeria and produces a valuable natural resin, which is generally known as

\footnotetext{
CThis article is open access and licensed under the terms of the Creative Commons Attribution License (http://creativecommons.org/licenses/by/4.0/) which permits unrestricted, use, distribution and reproduction in any medium, or format for any purpose, even commercially provided the work is properly cited. Attribution - You must give appropriate credit, provide a link to the license, and indicate if changes were made. 
Chios mastic gum. The resin is collected by wounding the trunk and thick branches (Koç et al., 2014a). Mastic gum has been used by healers for several treatments, such as for hypertension, coughs, sore throats, eczema, gastrointestinal disturbances, kidney stones, hepatobiliary disorders, gynaecological diseases, fractures, wounds and jaundice (Al-Habbal et al., 1984; Koç et al., 2014b; Imtiyaz et al., 2013). In the present, the mastic has been commonly used as a flavor or supplement in foods, sweets, beverages, chewing gum, toothpaste and lotions (Koç et al., 2014a).

Mastic gum has been reported as a natural compound with widespread biological properties including antimicrobial and antifungal (Tassou and Nychas, 1995; Magiatis et al., 1999; Koutsoudaki et al., 2005), anticancer (Balan et al., 2007; He et al., 2006; Li et al., 2007; Loutrari et al., 2011), antioxidant, antiinflammatory (Mahmoudi et al., 2013; Triantafyllou et al., 2011), antiparasitic (Eldin and Badawy, 2013), antiatheromatic (Paraschos et al., 2008), hypolipidemic (Paraschos et al., 2008), and hepatoprotective/cardioprotective(Triantafyllou et al., 2007) effects.

The previous chemical investigations reported that the essential oil of mastic contains several secondary metabolites including medicinally important ones (Boelens and Jimenez, 1991; Papageorgiou et al., 1991; Castola et al., 2000; Koutsoudaki et al., 2005; Miyamoto et al., 2014).

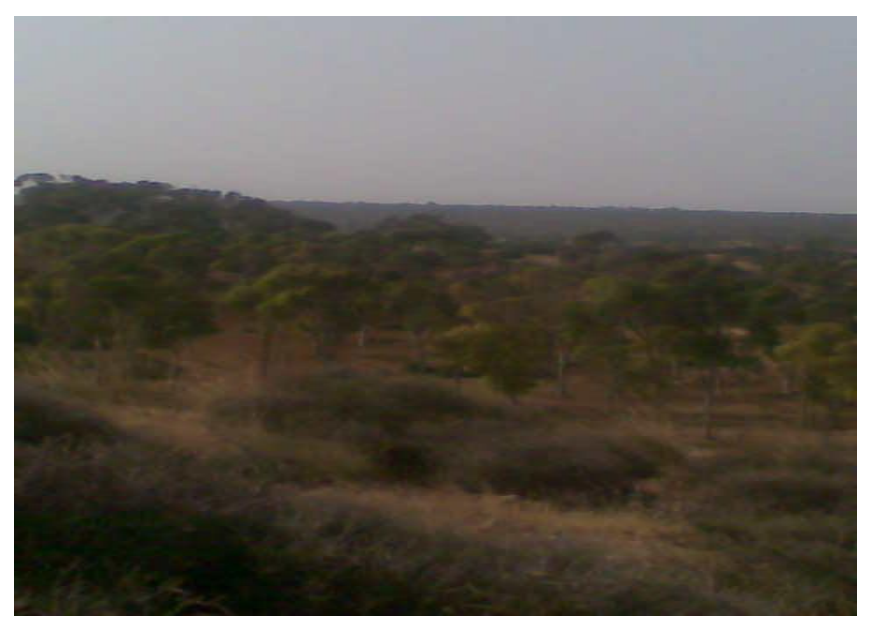

Photo 1.The forest of Moulay Ismail, Algeria.
Aim of the present work was to investigate the antimicrobial activity of mastic gum essential oil of western Algerian Pistacia lentiscus against E. coli and $S$. aureus.

\section{Materials and methods \\ Plant material and essential oil extraction}

$P$. lentiscus resin used in experiments was crude normal, collected during April-June 2010, which corresponds to the period of oleoresin formation, from the forest of Moulay Ismail (Photo 1), about $40 \mathrm{~km}$ far from Mascara city, northwest of Algeria. To collect the resin, fine incisions are made in the bark, and drops of sap appear and dry in large, odorous yellow droplets (Photo 2), then picking off.

The ethanol extracts were obtained by weighing out a fraction $2.6 \mathrm{~g}$ of $P$. lentiscus resin and soaking in $260 \mathrm{ml}$ of ethanol $96^{\circ}$. The combined hydroalcoholic extract filtered through filter paper and concentrated to dryness under reduced pressure using a rotary evaporator, then stored in the dark at $4^{\circ} \mathrm{C}$ with no air contact. The extract was further used for screening purposes (Bachir and Benali, 2009).

\section{Microbial strains}

The bacteria used in the microbiological assays were A Gram positive bacterium; Staphylococcus aureus ATCC 25923 and Gram negative bacteria; Escherichia coli ATCC 25922. Standard cultures of bacteria from the American Type Culture Collection (ATCC) were obtained from the Hospital University Center (HUC) of Oran City, situated in the North West of Algeria.

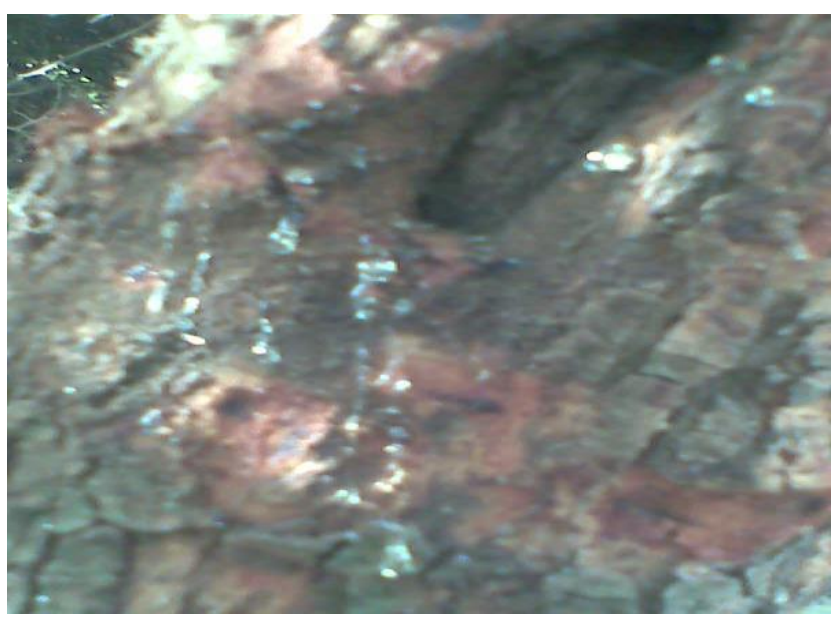

Photo 2. Harvest of the resin. 


\section{Assessment of inhibition of bacterial growth}

Agar disc diffusion method was used to demonstrate the antibacterial properties of $P$. lentiscus resin extracts.

For disc diffusion, a suspension of each sample tested micro-organism diluted prior to $10^{-}$ $1,10^{-2}$ and $10^{-3}-\left(1 \mathrm{ml}\right.$ of $10^{8}$ cells $\left./ \mathrm{ml}\right)$ was spread on a solid agar medium in Petri dishes (MuellerHinton agar). Sterile paper disks in $6 \mathrm{~mm}$ diameter were impregnated with the resin oil with the capacity of $13 \mu \mathrm{L}$. These impregnated disks were applied on solid agar medium in petri dishes by pressing slightly. The plates were incubated at $37^{\circ} \mathrm{C}$ for $24 \mathrm{~h}$, and the diameters of inhibition zones were measured in millimetres (Bachir and Benali, 2012).

\section{Results and discussions}

Antimicrobial activity of resin oil determined by disc diffusion

From the preliminary screening studies by disc diffusion method, it was observed that only $S$. aureus was susceptible to resin oil of P. lentiscus. The results shown in Fig. 1 and table 1clearly indicate that resin essential oil is moderate antibacterial towards $S$. aureus and inactive against E. coli. Considerable variation in inhibition zone sizes ranging from $08-20 \mathrm{~mm}$ was observed in $S$. aureus isolates depending on their sensitivity towards resin oil. The largest zone of inhibition was obtained for with $10^{-1}$ and $10^{-2}$ dilutions of $P$. lentiscus on $10^{-1}$ and $10^{-2}$ dilutions of $S$. aureus and the lowest for $10^{-2}$ and $10^{-3}$ dilutions of resin oil on $10^{-2}$ and $10^{-3}$ dilutions of $S$. aureus.

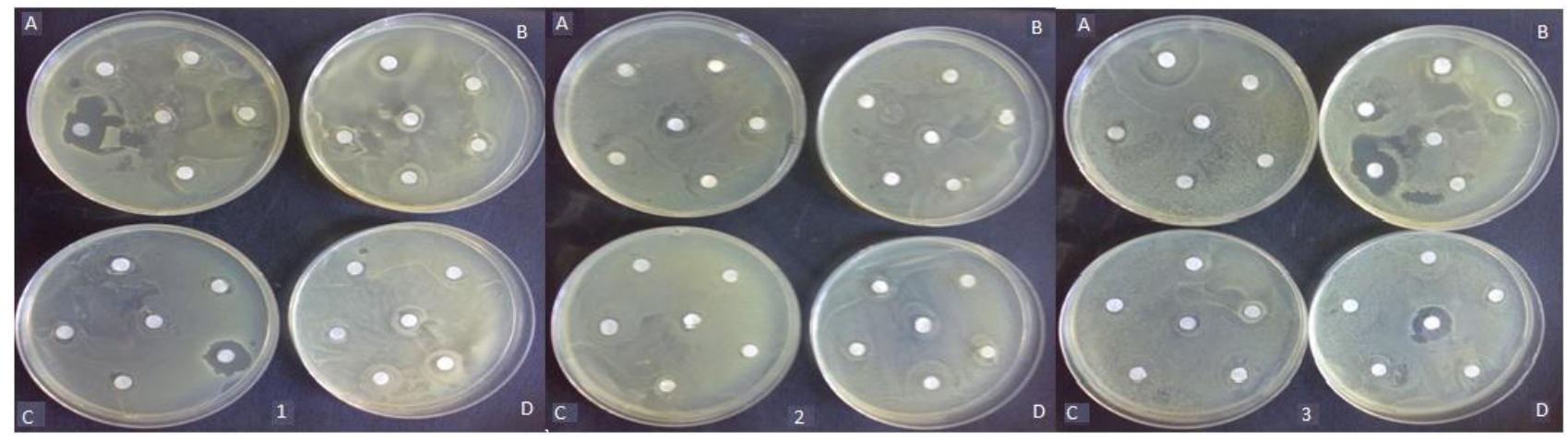

1A : dilution $10^{-1}$ of resin oil; $\quad \mathrm{B}$ : dilution $10^{-2}$ of resin oil; $\mathrm{C}$ : dilution $10^{-3}$ of resin oil; $\quad \mathrm{D}:$ dilution $10^{-4}$ of resin oil 1 dilution $10^{-1}$ of $S$. aureus - 2 dilution $10^{-2}$ of $S$. aureus - 3 dilution $10^{-3}$ of $S$. aureus

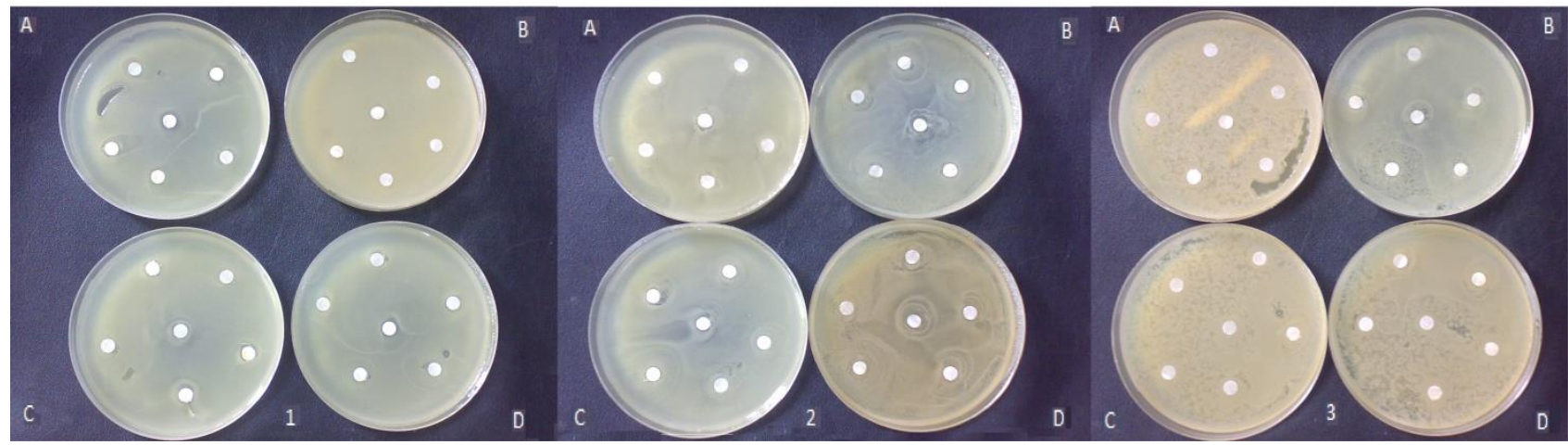

1A : dilution $10^{-1}$ of resin oil; $\quad \mathrm{B}$ : dilution $10^{-2}$ of resin oil; $\mathrm{C}$ : dilution $10^{-3}$ of resin oil; $\quad \mathrm{D}:$ dilution $10^{-4}$ of resin oil 1 dilution $10^{-1}$ of E. coli - 2 dilution $10^{-2}$ of E. coli - 3 dilution $10^{-3}$ of E. coli

Fig. 1. Results of the antibacterial activity evaluation of the resin essential oil of P. lentiscus against E. coli and S. aureus, using the agar disc diffusion method. 
Table 1. Antimicrobial activity evaluation of the essential oil resin of P. lentiscus with Agar disc diffusion method.

\begin{tabular}{|c|c|c|c|c|c|c|}
\hline \multirow{2}{*}{$\begin{array}{l}\text { Bacterial } \\
\text { strain }\end{array}$} & & \multicolumn{4}{|c|}{ Resin oil dilutions } & \multirow[b]{2}{*}{ Control } \\
\hline & & $10^{-1}$ & $10^{-2}$ & $10^{-3}$ & $10^{-4}$ & \\
\hline E. coli & $10^{-1}$ & & & & & \\
\hline & $\begin{array}{l}10^{-2} \\
10^{-3}\end{array}$ & NI & $\mathrm{NI}$ & $\mathrm{NI}$ & NI & $\mathrm{NI}$ \\
\hline S.aureus & $\begin{array}{l}10^{-1} \\
10^{-2} \\
10^{-3}\end{array}$ & $\begin{array}{l}20 \mathrm{~mm} \\
8 \mathrm{~mm} \\
16 \mathrm{~mm}\end{array}$ & $\begin{array}{l}9 \mathrm{~mm} \\
20 \mathrm{~mm} \\
8 \mathrm{~mm}\end{array}$ & $\mathrm{NI}$ & NI & NI \\
\hline
\end{tabular}

Results of this study demonstrated that the gram-negative bacteria (E. coli) was resistant to all tested dilutions of the resin essential oil but the gram-positive bacteria (S. aureus) was susceptible when it was tested with the dilutions of $10^{-1}$ and $10^{-2}$ of same extract. Usually there is a trend that the essential oils always act on the gram-positive than the gram-negative bacteria (Bidlack et al., 2000). It may be attributed to sensitivity between Gram-positive and Gram-negative bacteria in morphological differences. The Gram-positive bacteria should be more susceptible having only an outer peptidoglycan layer which is not an effective permeable barrier (Santos et al., 2013).

These results confirm previous reports of antibacterial activity for essential oils from resin of $P$. lentiscus have been shown to be more effective against the gram-positive than the gram-negative bacteria (Tassou et Nychas, 1995; Hussain and Tabji, 1997; AliShtayeh et al., 1998; Magiatis et al., 1999; Koutsoudaki et al., 2005; Benhammou et al., 2008; Gkogka et al., 2013). Aksoy et al. (2006), have tested the resin oil of $P$. lentiscus against Streptococcus mutans (Gram positive bacteria like $S$. aureus) and they reported its susceptibility to this extract. Many authors conducted studies which support the effectiveness effect of the essential oil of aerial parts of this plant on S. aureus (Iauk et al., 1996; Bonsignore et al., 1998; Benhammou et al., 2008; Derwich et al., 2010). On the other hand, and in contradiction to the results obtained by this study, Sakagami et al. (2009) found that these oils were more effective against the two bacteria.

For several years, essential oils of resin of $P$. lentiscus are known for their antimicrobial activity which reported in several studies. These antibacterial properties could be mainly attributed to its major chemical constituents. As reported by Kokolakis el al. (2010), Kordali et al.
(2003), Koutsoudaki et al. (2005) and Magiatis et al. (1999), the essential oil from resin of $P$. lentiscus presented $\alpha$-pinene, $\beta$-pinene and limonene as the major components and are wellknown chemicals having antimicrobial potentials (Dorman and Deans, 2000; Magwa et al., 2006).

\section{Conclusion}

$P$. lentiscus, an important medicinal plant is useful in the treatment of wide range of disorders. The present investigation clearly indicates that the essential oil of $P$. lentiscus resin exhibited antibacterial activity against $S$. aureus. On the basis of the present finding, the resin of $P$. lentiscus have antibacterial properties that can be utilized in the production of commercial bactericides and against infections and/or diseases caused by $S$. aureus.

\section{References}

Aksoy, A., Duran, N., \& Koksal, F. (2006). In vitro and in vivo antimicrobial effects of mastic chewing gum against Streptococcus mutans and mutans streptococci. Archives of Oral Biology, 51(6), 476-481.

Al-Habbal, M. J., Al-Habbal, Z., \& Huwez, F. U. (1984). A double-blind controlled clinical trial of mastic and placebo in the treatment of duodenal ulcer. Clinical and Experimental Pharmacology and Physiology, 11(5), 541-544.

Ali-Shtayeh, M. S., Yaghmour, R. M. R., Faidi, Y. R., Salem, K., \& Al-Nuri, M. A. (1998). Antimicrobial activity of 20 plants used in folkloric medicine in the Palestinian area. Journal of Ethnopharmacology, 60 (3), 265271.

Bachir, G. R., \& Benali M. (2009). Essential oil from gum of Pistacia atlantica Desf:: screening of antimicrobial activity. African Journal of Pharmacy and Pharmacology, 3(3), 087091. 
Bachir, G. R., \& Benali, M. (2012). Antibacterial activity of the essential oils from the leaves of Eucalyptus globulus against Escherichia coli and Staphylococcus aureus. Asian Pacific Journal of Tropical Biomedicine, 2(9), 739-742.

Bachir, G. R., Otsmane, M., \& Sebaa, F. (2017). Antimicrobial activity of essential oils of Juniperus phoenicea from North Western Algeria. Journal of Medicinal Botany, 1, 01-07.

Balan, K. V., Prince, J., Han, Z., Dimas, K., Cladaras, M., Wyche, J. H., \& Pantazis, P. (2007). Antiproliferative activity and induction of apoptosis in human colon cancer cells treated in vitro with constituents of a product derived from Pistacia lentiscus L. var. chia. Phytomedicine, 14(4), 263-272.

Belhadj, S. (1999). Pistachio situation in Algeria. FAO-IHEAM Nucis. Newsletter. 8, 30.

Benhammou, N., Bekkara, F. A., \& Panovska, T. K. (2008). Antioxidant and antimicrobial activities of the Pistacia lentiscus and Pistacia atlantica extracts. African Journal of Pharmacy and Pharmacology, 2(2), 022-028.

Bidlack, W. R., Omaye, S. T., Meskin, M. S., \& Topham, D. K. (Eds.). (2000). Phytochemicals as Bioactive Agents. CRC press.

Boelens, M. H., \& Jimenez, R. (1991). Chemical composition of the essential oils from the gum and from various parts of Pistacia lentiscus L. (mastic gum tree). Flavour and Fragrance Journal, 6(4), 271-275.

Bonsignore, L., Cottiglia, F., and Loy, G. (1998). Antibacterial activity of Pistacia lentiscus aerial parts. Fitoterapia, 69, 537-538.

Castola, V., Bighelli, A., \& Casanova, J. (2000). Intraspecific chemical variability of the essential oil of Pistacia lentiscus L. from Corsica. Biochemical Systematics and Ecology, 28(1), 79-88.

Chambers, H. F., \& DeLeo, F. R. (2009). Waves of resistance: Staphylococcus aureus in the antibiotic era. Nature Reviews in Microbiology, 7(9), 629-641.

De Kraker, M. E., Davey, P. G., Grundmann, H., \& BURDEN Study Group. (2011). Mortality and hospital stay associated with resistant Staphylococcus aureus and Escherichia coli bacteremia: estimating the burden of antibiotic resistance in Europe. PLoS Med, 8(10), e1001104.
Derwich, E., Manar, A., Benziane, Z., \& Boukir, A. (2010). GC/MS analysis and in vitro antibacterial activity of the essential oil isolated from leaf of Pistacia lentiscus growing in Morocoo. World Applied Sciences Journal 8(10), 1267-1276.

Dorman, H. J. D., \& Deans, S. G. (2000). Antimicrobial agents from plants: antibacterial activity of plant volatile oils. Journal of Applied Microbiology, 88(2), 308316.

Eldin, H. M. E., \& Badawy, A. F. (2015). In vitro anti-Trichomonas vaginalis activity of Pistacia lentiscus mastic and Ocimum basilicum essential oil. Journal of Parasitic Diseases, 39(3), 465-473.

Embrey, M., Hunter, P., Sellwood, J., Wyn-Jones, P., Percival, S. L., \& Chalmers, R. (2004). Microbiology of Waterborne diseases: Microbiological Aspects and Risks. Academic Press.

Enright, M. C., Day, N. P., Davies, C. E., Peacock, S. J., \& Spratt, B. G. (2000). Multilocus sequence typing for characterization of methicillin-resistant and methicillin-susceptible clones of Staphylococcus aureus. Journal of clinical microbiology, 38(3), 1008-1015.

Gagliotti, C., Balode, A., Baquero, F., Degener, J., Grundmann, H., Gür, D., \& Rossolini, G. M. (2011). Escherichia coli and Staphylococcus aureus: bad news and good news from the European Antimicrobial Resistance Surveillance Network (EARS-Net, formerly EARSS), 2002 to 2009. Eurosurveillance.

Galvão Rodrigues, F. F., Costa, J. G. M., Rodrigues, F. F. G., \& Campos, A. R. (2013). Study of the interference between Plectranthus species essential oils from Brazil and aminoglycosides. Evidence-Based Complementary and Alternative Medicine, 2013.

Gkogka, E., Hazeleger, W. C., Posthumus, M. A., \& Beumer, R. R. (2013). The antimicrobial activity of the essential oil of Pistacia lentiscus var. Chia. Journal of Essential Oil Bearing Plants, 16(6), 714-729.

He, M. L., Yuan, H. Q., Jiang, A. L., Gong, A. Y., Chen, W. W., Zhang, P. J., \& Zhang, J. Y. (2006). Gum mastic inhibits the expression and function of the androgen receptor in prostate cancer cells. Cancer, 106(12), 25472555 . 
Hormaza, J. I., \& Wünsch, A. (2011). Pistacia. In Wild Crop Relatives: Genomic and Breeding Resources (pp. 119-128). Springer Berlin Heidelberg.

Hossain, M. T., Siddique, M. P., Hossain, F. M. A., Zinnah, M. A., Hossain, M. M., Alam, M. K., \& Choudury, K. A. (2008). Isolation, identification, toxin profile and antibiogram of Escherichia coli isolated from broilers and layers in Mymensingh district of Bangladesh. Bangladesh Journal of Veterinary Medicine, 6(1), 1-5.

Hussain, H., and Tobji, R. S. (1997) Antibacterial screening of some Libyan medicinal plants. Fitoterapia, 68(5), 467-470.

Iauk, L., Ragusa, S., Rapisarda, A., Franco, S., \& Nicolosi, V. M. (1996). In vitro antimicrobial activity of Pistacia lentiscus L. extracts: preliminary report. Journal of Chemotherapy 8(3), 207-209.

Imtiyaz, S., Tariq, M., Ali, S. J., Chaudhary, S. S., \& Baig, M. G. (2013). Pistacia lentiscus Linn: Gum with immense medicinal potential. Spatula DD-Peer Reviewed Journal on Complementary Medicine and Drug Discovery, 3(2), 69-73.

Koç, İ., Akdemir, H., Onay, A., \& Çiftçi, Y. Ö. (2014a). Cold-induced genetic instability in micropropagated Pistacia lentiscus L. plantlets. Acta Physiologiae Plantarum 36(9), 2373-2384.

Koc, I., Onay, A., \& ÇİFTÇİ, Y. Ö. (2014b). In vitro regeneration and conservation of the lentisk (Pistacia lentiscus L.). Turkish Journal of Biology, 38(5), 653-663.

Kokolakis, A. K., Kouvarakis, A. N., \& Katerinopoulos, H. E. (2010). Effect of hydrodistillation with phosphoric acid on the yield of Chios mastic gum essential oil. Flavour and fragrance journal, 25(1), 48-53.

Kordali, S., Cakir, A., Zengin, H., \& Duru, M. E. (2003). Antifungal activities of the leaves of three Pistacia species grown in Turkey. Fitoterapia, 74(1), 164-167.

Koutsoudaki, C., Krsek, M., \& Rodger, A. (2005). Chemical composition and antibacterial activity of the essential oil and the gum of Pistacia lentiscus Var. chia. Journal of Agricultural and Food Chemistry, 53(20), 76817685.
Li, A., Zhang, M. J., \& Gu, H. (2007). Mechanisms of antiprostate cancer by gum mastic: NF- $x \mathrm{~B}$ signal as target. Acta pharmacologica sinica, 28(3), 446-452.

Loutrari, H., Magkouta, S., Papapetropoulos, A., \& Roussos, C. (2011). Mastic oil inhibits the metastatic phenotype of mouse lung adenocarcinoma cells. Cancers, 3(1), 789-801.

Magiatis, P., Melliou, E., Skaltsounis, A. L., Chinou, I. B., \& Mitaku, S. (1999). Chemical composition and antimicrobial activity of the essential oils of Pistacia lentiscus var. chia. Planta Medica, 65(08), 749-752.

Magwa, M. L., Gundidza, M., Gweru, N., \& Humphrey, G. (2006). Chemical composition and biological activities of essential oil from the leaves of Sesuvium portulacastrum. Journal of Ethnopharmacology, 103(1), 85-89.

Mahmoudi, M., Ebrahimzadeh, M. A., Nabavi, S. F., Hafezi, S., Nabavi, S. M., \& Eslami, S. H. (2010). Antiinflammatory and antioxidant activities of gum mastic. European Review in Medical and Pharmacological Science, 14(9), 765769.

Mezni, F., Maaroufi, A., Msallem, M., Boussaid, M., Khouja, M. L., \& Khaldi, A. (2012). Fatty acid composition, antioxidant and antibacterial activities of Pistacia lentiscus L. fruit oils. Journal of Medicinal Plants Research, 6(39), 5266-5271.

Miyamoto, T., Okimoto, T., \& Kuwano, M. (2014). Chemical composition of the essential oil of mastic gum and their antibacterial activity against drug-resistant Helicobacter pylori. Natural Products and Bioprospecting, 4(4), 227-231.

Oteo, J., Campos, J., Lázaro, E., Cuevas, Ó., García-Cobos, S., Pérez-Vázquez, M., \& of EARSS, S. M. (2008). Increased amoxicillinclavulanic acid resistance in Escherichia coli blood isolates, Spain. Emerging infectious diseases, 14(8), 1259.

Owlia, P., Saderi, H., Rasooli, I., \& Sefidkon, F. (2010). Antimicrobial characteristics of some herbal oils on Pseudomonas aeruginosa with special reference to their chemical compositions. Iranian Journal of Pharmaceutical Research, 107-114.

Papageorgiou, V. P., Mellidis, A. S., \& Argyriadou, N. (1991). The chemical composition of the essential oil of mastic 
gum. Journal of Essential Oil Research, 3(2), $107-$ 110.

Paraschos, S., Andreadou, I., Iliodromitis, E., Zoga, A., Magiatis, P., Mitaku, S., \& Kremastinos, D. T. (2008). Anti atheromatic and hypolipidemic activity of Chios mastic gum in anesthetized rabbits. Planta Medica, 74(09), PA343.

Parvizi $^{1}$, M., Doosti, A., \& Dehkordi, P. G. (2012). Detection of antibiotic resistance genes in Staphylococcus aureus strains isolated from cow's milk using multiplex PCR Assay. Journal of Pure and Applied Microbiology, 6(3), 1083-1088.

Sakagami, H., Kishino, K., Kobayashi, M., Hashimoto, K., Iida, S., Shimetani, A., \& Satoh, K. (2009). Selective antibacterial and apoptosis-modulating activities of mastic. In Vivo, 23(2), 215-223.

Santos, T. G., Dognini, J., Begnini, I. M., Rebelo, R. A., Verdi, M., Gasper, A. L. D., \& Dalmarco, E. M. (2013). Chemical characterization of essential oils from Drimys angustifolia miers (Winteraceae) and antibacterial activity of their major compounds. Journal of the Brazilian Chemical Society, 24(1), 164-170.

Tadesse, D. A., Zhao, S., Tong, E., Ayers, S., Singh, A., Bartholomew, M. J., \&
McDermott, P. F. (2012). Antimicrobial drug resistance in Escherichia coli from humans and food animals, United States, 1950 2002. Emerging Infectious Diseases, 18(5), 741.

Tassou, C. C., \& Nychas, G. J. E. (1995). Antimicrobial activity of the essential oil of mastic gum (Pistacia lentiscus var. chia) on Gram positive and Gram negative bacteria in broth and in model food system. International Biodeterioration \& Biodegradation, 36(3-4), 411420.

Triantafyllou, A., Bikineyeva, A., Dikalova, A., Nazarewicz, R., Lerakis, S., \& Dikalov, S. (2011). Anti-inflammatory activity of Chios mastic gum is associated with inhibition of TNF-alpha induced oxidative stress. Nutrition Journal, 10(1), 64.

Trop, M. (2010). Evolution of the resistance of Staphylococcus aureus to antibiotics at the Saint Camille Medical Center in Ouagadougou. Tropical Medicine, 70 (3), 241-244.

Waters, A. E., Contente-Cuomo, T., Buchhagen, J., Liu, C. M., Watson, L., Pearce, K., \& Keim, P. S. (2011). Multidrug-resistant Staphylococcus aureus in US meat and poultry. Clinical Infectious Diseases, 52(10), 1227-1230. 